\title{
A study on peart millet (Pennisetum glaucum L.) plant Biochemical and histochemical changes inoculated with indigenous AM fungi under Barren soil
}

\author{
Ajay Pal $\cdot$ Sonali-Pandey \\ Received: 11 April 2017 / Revised: 16 June 2017 / Accepted: 16 June 2017 \\ (C) Korean Society for Plant Biotechnology
}

\begin{abstract}
The soil organisms that develop beneficial Symbiotic relationships with plants roots and contribute to plant growth are mycorrhizal (AM) fungi. Arbuscular mycorrhizal inoculations change the growth and biochemical composition of the host plant and soil. Mycorrhizal root systems do augment the absorbing area of roots from 10 to 100 times thereby greatly improving the ability of the plants to utilize the soil resources. A pot experiment was conducted during the kharif seasons at Jaipur, Rajasthan, to find out the effects of three different indigenous AM fungi i.e. Glomus mosseae, Glomus fasciculatum and Gigaspora decipiens either single and in combination inoculation on biochemical and histochemical changes of Pearl millet (Pennisetum glaucum L.) grown under barren soil conditions. The AM fungus has shown to improve the tolerance of plant to drought stress. Experimental results showed that AM fungi treated plants improved their plants growths, biochemical and histochemical changes as compared to non-mycorrhizal treatments. The AM fungi inoculated plant was found to be attaining maximum plant biochemical and histochemical substances in Glomus mosseae (alone) and also Glomus mosseae + Glomus fasciculatum treatments.
\end{abstract}

Keywords AMfungi, Biochemical, Histochemical localization, Plant growth, Pearl millet (Pennisetum glaucum L.)

\footnotetext{
A. Pal

Research scholar, Department of Botany, JECRC University, Jaipur, 303905, India

S. Pandey $(\varangle)$

Associate Professor, Department of Botany, JECRC University, Jaipur, 303905, India

e-mail: drsonali17@gmail.com
}

\section{Introduction}

Soil infertility is a worldwide problem, which restricts plant growth and production in many parts of the world especially in arid and semiarid environment. It is one of the major challenges for the sustainable food security within the available land resources. The agricultural sustainability could be viewed as maximum plant production with minimum soil loss. The establishment of plant cover is the most important step in restoration of degraded areas (Hanjra and Qureshi 2010).

The total land area of Rajasthan is 3,42,239 sq. km out of which $45.25 \%$ is characterized as wasteland. The soil organisms that develop beneficial symbiotic relationships with plants roots and contribute to plant growth are called mycorrhizal fungi (Smith and Read 2008). Many researchers have indicated that arbuscular mycorrhizal (AM) fungi are capable of alleviating the adverse effects of drought on plant growth (Jayne and Quigley, 2014). With the established symbiosis, AM fungi acquired carbon from host plant and in return supplied host plant with water and mineral nutrients (Smith and Read 2008).

Pearl millet is a major warm season coarse grain cereal; the major pearl millet growing states in India are Rajasthan, UP, Haryana, Gujarat and Maharashtra. Pearl millet (Pennisetum glaucum L.) plays a significant role in nutritious food as it is a rich source of vitamin, mineral and protein.

Against this background of information and utility of AM fungi in re-establishment of soil fertility, the present investigation was conducted in Jaipur region. Therefore, the reason of the present study was to investigate the effect of different treatments of AM fungi on plant biochemical and histochemical changes of pearl millet plants grown under barren soil/ semi-arid environments. 


\section{Materials and Methods}

The experimental area was located in Jaipur, the capital city of the Rajasthan, India is situated in the eastern border of Thar Desert, and a semi-arid land (coordinates $26^{\circ} 55^{\prime}$ $19.45^{\prime \prime} \mathrm{N}$ and $\left.75^{\circ} 46^{\prime} 43.98^{\prime \prime} \mathrm{E}\right)$.

\section{Isolation of AM fungi and Mass Multiplication}

The AM fungi was isolated from the plant roots and their rhizospheric soil of seasonal plants cultivated from the field by 'Wet sieving and decanting technique' (Gerdemann and Nicolson 1963) and was identified with manual of Scheneck and Perez (1990) and using synoptic keys of Trappe (1982). The mass culture of specified AM species was obtained through pure culturing "Funnel Technique" of Menge and Timmer (1982) using Sorghum bicolor. The pearl millet [Pennisetum glaucum L. (Raj-171)] was selected as the host plant for this study.

\section{Experimental Setup and Design}

The mud pots $(25 \times 25 \mathrm{~cm})$ were taken and filled with airdried sterilized soil (3-4 kg) collected from barren soil and with $5-10 \%(\mathrm{w} / \mathrm{w})$ of the inoculums of each AM fungi and with surface sterilized seeds of Pearl millet were planted. These treatments were maintained i.e.- $\mathrm{T}_{1}$ - Inoculated with Glomus mosseae (alone), $\mathrm{T}_{2}$ - Inoculated with Glomus fasciculatum, $\mathrm{T}_{3}$ - Inoculated with Gigaspora decipiens, $\mathrm{T}_{4}$ - Inoculated with Glomus mosseae + Glomus fasciculatum (combined), $\mathrm{T}_{5}$ - Inoculated with Glomis mosseae + Gigaspora decipiens, $\mathrm{T}_{6}$ - Inoculated with Glomus fasciculatum + Gigaspora decipiens and $\mathrm{T}_{0^{-}}$Control (without $\mathrm{AM}$ fungi).

Analysis of plant biochemical's and histochemical localization

Estimation of chlorophyll pigments- The chlorophyll pigments in the fresh leaves were estimate following the method of Arnon (1949). Estimation of Total phenols - Estimation of phenols using Folin-Ciocalteu's reagent by Bray and Thorpe (1954). Estimation of sugar (Total and reducing sugar) was with Nelson-Somogyi method, Nelson (1944) and the estimation of Starch content was by Chinoy (1939). Mycorrhizal root colonization was studied by 'Rapid clearing and staining method' of Phillips and Hayman (1970).

Histochemical changes

Localization of total protein- Proteins were localized by 'mercuric bromophenol blue (MBB method)' (Mazia et al. 1953; Dubey and Trivedi 2012). Localization of polysaccharidePolysacchride was localized in host plants root by 'periodic acid Schiff's (PAS) technique' (Jensen, 1962). Localization of Peroxidase- Peroxidase enzyme was localized by 'Benzidine method' of host plants roots. Localization of Alkaline phosphate- Alkaline phosphate was localized with $\mathrm{Na}-\alpha$ -naphthyl acid phosphate and fast blue after digest host plant roots with cellulose-pectinase solution. Localization of succinate dehydrogenase- Succinate dehydrogenase localization with Nitro blue tetrazolium (NBT) and mounted the sections with glycerol and observed was in stereomicroscope.

All determinations of plants biochemical parameters and measurements were conducted using 3 replicates. The value for each sample was calculated as the mean \pm SE Statistical analyses was carried out using Microsoft Excel 2007.

\section{Results and Discussion}

In the present studies, an attempt was to analyze and study the biochemical as well as histochemical changes of test plant invaded with different combination of AM fungi species with compared to control.

\section{Biochemical changes}

The different treatment of AM inoculated plants showed increased level of chlorophyll content. It was noticed that, in this present study the maximum total chlorophyll content $\left(2.03 \pm 0.02 \mathrm{mg} / \mathrm{g}^{-1}\right)$ was noted in G. mosseae (T1) fungi treatment followed by $\left(1.98 \pm 0.08 \mathrm{mg} / \mathrm{g}^{-1}\right) \mathrm{G}$. mosseae + G. fasciculatum (T4) fungi plants respectively (site I) compared to control (table-1). The present study showed significant variations of phenol content from different AM fungi inoculated plants; Maximum phenol content was found in stem (1.80 \pm $0.20 \mathrm{mg} / \mathrm{g}^{-1}$ ) of G. mosseae + G. fasciculatum (T4) followed by $1.78 \pm 0.03 \mathrm{mg} / \mathrm{g}^{-1}$ of $\mathrm{G}$. mosseae (T1) treated plant of site (I).

The different treatment of AM inoculated plants showed increased level of total sugar and reducing sugar content. The maximum total sugar content was found in stem part $13.16 \pm 0.17 \mathrm{mg} / \mathrm{g}^{-1}$ of $G$. mosseae $\left(\mathrm{T}_{1}\right)$ followed by $13.13 \pm 0.15 \mathrm{mg} / \mathrm{g}^{-1}$ G. mosseae + G. fasciculatum $\left(\mathrm{T}_{4}\right)$ treated host plants respectively in site-I and highest reducing sugar $5.22 \pm 0.08 \mathrm{mg} / \mathrm{g}^{-1}$ was found in inoculated with $G$. mosseae $\left(\mathrm{T}_{1}\right)$ (site I) host plant.

Plants store carbohydrate in the form of starch, which is produced by photosynthesis. The maximum total starch 
Table 1 Biochemicals (chlorophyll, total phenol, sugars and starch) content (mg/g) and root-mycorrhizal colonization (\%) of pearl millet (Pennisetum glaucum L.) plants treated with diff. AM fungi

\begin{tabular}{|c|c|c|c|c|c|c|c|c|c|c|c|c|c|}
\hline \multirow{3}{*}{$\begin{array}{l}\text { Sample } \\
\text { Site }\end{array}$} & \multirow{3}{*}{$\begin{array}{l}\text { Parameters/ } \\
\text { Treatments }\end{array}$} & \multicolumn{3}{|c|}{$\begin{array}{c}\text { Chlorophyll mg/g } \\
\text { (Fresh wt.) }\end{array}$} & \multirow{2}{*}{\multicolumn{2}{|c|}{$\begin{array}{c}\text { Total phenol } \\
\text { mg/g (Fresh wt.) }\end{array}$}} & \multicolumn{4}{|c|}{ Sugars mg/g (Fresh wt.) } & \multirow{2}{*}{\multicolumn{2}{|c|}{$\begin{array}{l}\text { Starch mg/g } \\
\text { (Fresh wt.) }\end{array}$}} & \multirow{3}{*}{$\begin{array}{c}\text { Mycorrhizal } \\
\text { Colonization } \\
\%\end{array}$} \\
\hline & & \multirow{2}{*}{ chl a } & \multirow{2}{*}{ chl b } & \multirow{2}{*}{ Total chl } & & & \multicolumn{2}{|c|}{ Total sugar } & \multicolumn{2}{|c|}{ reducing Sugar } & & & \\
\hline & & & & & Root & Shoot & Root & Shoot & Root & Shoot & Root & Shoot & \\
\hline \multirow{7}{*}{ Site I } & $\mathrm{T}_{1}$ & $1.40 \pm 0.02$ & $63 \pm 0.01$ & $2.03 \pm 0.02$ & $0.95 \pm 0.05$ & $1.78 \pm 0.03$ & $10.23 \pm 0.12$ & $13.16 \pm 0.17$ & $4.23 \pm 0.11$ & $5.22 \pm 0.08$ & $3.73 \pm 0.25$ & $6.43 \pm 0.11$ & 94 \\
\hline & $\mathrm{T}_{2}$ & $1.38 \pm 0.01$ & $0.60 \pm 0.01$ & $1.98 \pm 0.03$ & $0.92 \pm 0.03$ & $1.77 \pm 0.04$ & $10.01 \pm 0.04$ & $13.03 \pm 0.20$ & $4.21 \pm 0.03$ & $5.21 \pm 0.30$ & $3.60 \pm 0.17$ & $6.53 \pm 0.15$ & 87 \\
\hline & $\mathrm{T}_{3}$ & $1.16 \pm 0.06$ & $0.53 \pm 0.06$ & $1.69 \pm 0.11$ & $0.78 \pm 0.03$ & $1.51 \pm 0.09$ & $8.11 \pm 0.13$ & $11.79 \pm 0.45$ & $3.36 \pm 0.35$ & $4.77 \pm 0.19$ & $3.10 \pm 0.10$ & $4.70 \pm 0.26$ & 61.5 \\
\hline & $\mathrm{T}_{4}$ & $1.39 \pm 0.03$ & $0.59 \pm 0.05$ & $1.98 \pm 0.08$ & $0.89 \pm 0.05$ & $1.80 \pm 0.20$ & $9.99 \pm$ & 1313 & $4.20 \pm 0.11$ & $5.20 \pm 0.22$ & $3.63 \pm 0.05$ & $6.50 \pm$ & 92 \\
\hline & $\mathrm{T}_{5}$ & $1.34 \pm 0.01$ & $0.55 \pm 0.02$ & $1.89 \pm 0.03$ & $0.82 \pm 0.01$ & $1.65 \pm 0.01$ & $9.33 \pm 0.27$ & $12.63 \pm 0.25$ & $4.09 \pm 0.27$ & $4.96 \pm 0.11$ & $3.46 \pm 0.23$ & $5.76 \pm 0.25$ & 84 \\
\hline & $\mathrm{T}_{6}$ & $1.30 \pm 0.01$ & $0.52 \pm 0.01$ & $1.82 \pm 0.02$ & $0.80 \pm 0.02$ & $1.60 \pm 0.02$ & $8.77 \pm 0.13$ & $12.02 \pm 0.06$ & $3.88 \pm 0.10$ & $4.88 \pm 0.10$ & $3.36 \pm 0.20$ & $5.56 \pm 0.11$ & 81 \\
\hline & (Control) & $0.79 \pm 0.02$ & $0.40 \pm 0.01$ & $1.19 \pm 0.02$ & $0.68 \pm 0.06$ & $1.38 \pm 0.04$ & $7.65 \pm 0.55$ & $10.22 \pm 0.25$ & $3.13 \pm 0.15$ & $4.06 \pm 0.15$ & $2.76 \pm 0.15$ & $3.90 \pm 0.15$ & Nil \\
\hline \multirow{7}{*}{ Site II } & $\mathrm{T}_{1}$ & $1.36 \pm 0.02$ & $0.60 \pm 0.01$ & $1.96 \pm 0.02$ & $0.72 \pm 0.04$ & $1.58 \pm 0.04$ & $10.06 \uplus 0.25$ & $12.98 \pm 0.15$ & $4.27 \pm 0.32$ & $5.06 \pm 0.12$ & $4.03 \pm 0.15$ & $5.86 \pm 0.20$ & 90 \\
\hline & $\mathrm{T}_{2}$ & $1.36 \pm 0.03$ & $0.58 \pm 0.01$ & $1.94 \pm 0.04$ & $0.72 \pm 0.05$ & $1.52 \pm 0.03$ & $9.97 \pm 0.35$ & $12.90 \pm 0.05$ & $4.28 \pm 0.30$ & $5.03 \pm 0.15$ & $3.93 \pm 0.20$ & $5.52 \pm 0.06$ & 89 \\
\hline & $\mathrm{T}_{3}$ & $1.00 \pm 0.02$ & $47 \pm 0.01$ & 1. & 0. & 1. & 0 & 11 & $9 \pm 0.06$ & 28 & $3.20 \pm 0.10$ & $4.00 \pm$ & 53 \\
\hline & $\mathrm{T}_{4}$ & $1.35 \pm 0.02$ & $0.57 \pm 0.02$ & $1.92 \pm 0.04$ & $0.71 \pm 0.03$ & $1.56 \pm 0.07$ & $9.94 \pm 0.33$ & $12.90 \pm 0.20$ & $4.27 \pm 0.25$ & $5.05 \pm 0.12$ & $3.83 \pm 0.15$ & $5.50 \pm 0.10$ & 89 \\
\hline & $\mathrm{T}_{5}$ & $1.31 \pm 0.06$ & $0.55 \pm 0.01$ & $1.86 \pm 0.07$ & $0.67 \pm 0.04$ & $1.51 \pm 0.06$ & $9.12+0.17$ & $12.02+0.16$ & $4.02 \pm 0.18$ & $4.86 \pm 0.15$ & $3.50 \oplus 0.10$ & $5.16 \pm 0.20$ & 83 \\
\hline & $\mathrm{T}_{6}$ & $1.28 \pm 0.1$ & $0.51 \pm 0.01$ & $1.79 \pm 0.01$ & $0.64 \pm 0.04$ & $1.46 \pm 0.07$ & $8.82 \pm 0.15$ & $11.74 \pm 0.21$ & $3.25 \pm 0.16$ & $4.69 \pm 0.19$ & $3.36 \pm 0.11$ & $4.72 \pm 0.26$ & 76.8 \\
\hline & $\mathrm{T}_{0}$ (Control) & $0.76 \pm 0.03$ & $0.38 \pm 0.01$ & $1.14 \pm 0.01$ & $0.50 \pm 0.04$ & $1.24 \pm 0.15$ & $7.14 \pm 0.21$ & $9.80 \pm 0.21$ & $2.86 \pm 0.06$ & $3.97 \pm 0.12$ & $2.70 \pm 0.17$ & $3.83 \pm 0.11$ & Nil \\
\hline
\end{tabular}

Data represents an average of 3 replicates indicates \pm SE, $T$ - treatment with diff. AM fungi sps.

content $6.53 \pm 0.15 \mathrm{mg} / \mathrm{g}^{-1}$ increase was found in inoculated of G. fasciculatum $\left(\mathrm{T}_{2}\right)$ followed by $6.50 \pm 0.17 \mathrm{mg} / \mathrm{g}^{-1}$ of G. mosseae + G. fasciculatum $\left(\mathrm{T}_{4}\right)$ treatments host plants respectively in site-I (table-1).

As reported earlier, the Arbuscular mycorrhizal fungi increase plant growth (Pennisetum glaucum) by enhancing photosynthetic activity, plant biochemical content and also nutrient uptake under abiotic stress conditions (Borde et al. 2011).

\section{Mycorrhizal-root colonization}

Treatments with AM fungal inoculation showed significant increase in root colonization over control. The root colonization percentage was observed to be highest in $\mathrm{T}_{1}(94 \%)$ followed by $\mathrm{T}_{4}(88 \%)$ (Site I) performed on par with the control (table-1).

\section{Histochemicals changes}

The histochemical localization of total protein stained with blue colour (fig.1 A-B). The total protein content showed an increase in the AM fungi infected roots as compared to the control plant roots. In plants root (T.S) the insoluble polysaccharides grain stained with the magenta colour (fig.1 C-D). Am fungi treated plants root-cell showed a higher polysaccharide grain in cortex portion compared to control. The plant root (T.S) cell presence of blue-black stain indicates that the enzyme of peroxidase (fig. 1 E-F). The darkening (blackish brown) of the host plant root cell contents compare to control reveals the presence of enzymes alkaline phosphatase (fig. $1 \mathrm{G}-\mathrm{H}$ ). The Appearance of the purple colour indicates the presence of succinate dehydrogenase enzyme in plant roots (T.S) (fig. 1 I-J). More amount of succinate dehyrogenase enzyme was seen in Am fungi infected roots as compared to non-treated plant (control).

Similar findings were observed by Abdel-Fattah and Asrar (2012) and Rabie and Almadini (2005), colonization of host plants by different species of arbuscular mycorrhizal fungi significantly increased Phosphatases, Succinate dehyrogenase enzymes activity, total soluble protein and insoluble polysaccharide (Dubey and Trivedi, 2012) compared to those of non-mycorrhizal plants. This results of the study were consistent with previous reports of Jayne and Quigley (2014) the reported that The Am fungal species of Glomus mosseae was the most efficient for its ability to increase plant growth, histochemical and level of active arbuscular formation.

In conclusion, the different species of AM fungi application significantly increased pearl millet plant growth, biochemical as well as histochemical components as compared to the non-mycorrhizal plants. The importance of VAM fungi to sustainable agriculture and the ecosystem has led to its commercial development. 


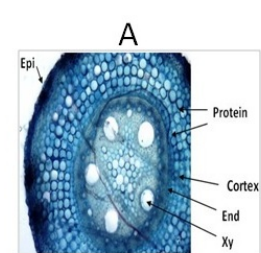

$\mathrm{E}$

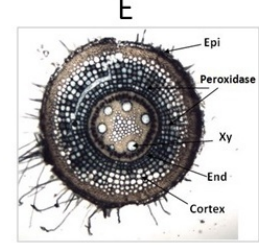

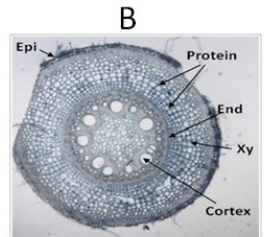

$\mathrm{F}$

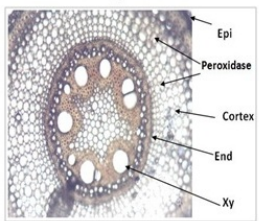

।

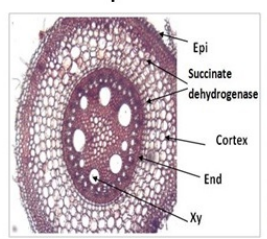

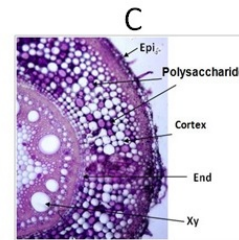

G

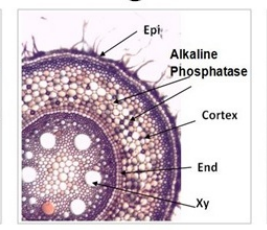

J

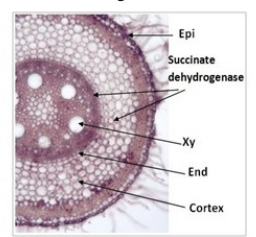

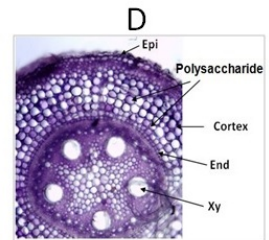

$\mathrm{H}$

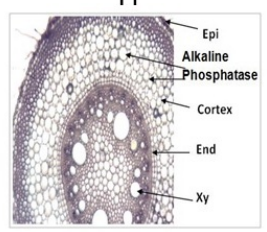

Fig. 1 Histochemical localization of total protein in AMF infected (A) plants root (T.S) and control (B), Polysaccharides in AMF infected plants root (C) and control (D), Peroxidase enzyme AMF infected plants root (E) and control (F), Alkaline phosphatase in AMF infected plants root $(\mathrm{G})$ and control $(\mathrm{H})$ and Succinate dehydrogenase in AMF infected plants root (I) and control (J) plants

\section{Acknowledgements}

The author is thankful to JECRC University for providing research facilities and also grateful to Dr. Anirudha Rishi, SP Institute of Biotechnology, Jaipur for their useful guidance.

\section{References}

Abdel-Fattah GM, Asrar AA (2012) Arbuscular mycorrhizal fungal application to improve growth and tolerance of wheat (Triticum aestivum L.) plants Brown in saline soil. Acta Physiol Plant 34:267-277

Arnon DL (1949) A copper enzyme is isolated chloroplast polyphenol oxidase in Beta Vulgaries. Plant Physiol 24:1-15

Borde M, Dudhane M, Jite P (2011) Growth, photosynthetic activity and antioxidant responses of mycorrhizal and non-mycorrhizal bajra (Pennisetum glaucum) crop under salinity stress condition. Crop Protection 30:265-271

Bray HG, Thorpe WV (1954) Analysis of phenolic compounds of interest in metabolism. Methods of Biochemical Analysis 1:27-52

Chinoy JJ (1939) A new colorimetric method for the determination of starch applied to soluble starch, natural starches and flour, Part-I, Coloromatric determination of soluble starch. Microchimica Acta 26:132-142

Dubey W, Trivedi PC (2012) Histochemical localization of proteins and nucleic acids in healthy and meloidogyne incognita, infected okra (abelmoschus esculentus (1.) Moench). Indian Journal of Fundamental and Applied Life Sciences 2:345-354

Gerdemann JW, Nicolson TH (1963) Spores of mycorrhizal Endogone species extracted from soil by wet sieving and decanting. Trans. Brit. Mycol. Soc. 46:235-244

Hanjra M, Qureshi ME (2010) Global water crisis and future food security in an era of climate change. Food Policy, 35:365-377

Jayne B, Quigley M (2014) Influence of arbuscular mycorrhiza on growth and reproductive response of plants under water deficit: a meta-analysis. Mycorrhiza 24:109-119

Jensen WA (1962) Botanical Histochemistry. W H Freeman Co. London, pp.197

Mazia D, Brewer PA, Alfert TM (1953) The Cytochemical staining and measurement of protein with mercuric bromophenol blue. Biological Bulletin 104:57-67

Menge JA, Timmer LM (1982) Procedure for inoculation of plants with VAM in the laboratory, greenhouse and field. In Methods and Principles of Mycorrhizal Research, ed. N. C. Schenck, St. Paul, American Phytopathological Society, pp.59-68

Nelson N (1994) A photometric adaptation of the Somogyi method for determination of Glucose. Journal of Biological Chemistry 153:375-380

Phillips JM, Hayman DS (1970) Improved procedures for clearing and staining parasitic and vesicular-arbuscular mycorrhizal fungi for rapid assessment of infection. Trans Br Mycol Soc. 55:158-161

Rabie GH, Almadini AM (2005) Role of bioinoculants in development of salt tolerance of Vicia faba plants under salinity stress. Afr. J. Biotechnol. 4:210-220

Schenck NC, Perez Y (1990) Manual for the identification of VAM fungi, (Eds. Schenck N.C. and Perez). INVAM, university of Florida, Gainesville, Florida, U.S.A., pp.241

Smith SE, Read DJ (2008) Mycorrhizal Symbiosis. 3rd edition. Academic Press, New York, 2008

Trappe JM (1982) Synoptic keys to the genera and species of zygomycetous mycorrhizal fungi. Phytopathology 72:1102-1108 